\title{
AN EXPERIMENTAL CASE-BASED REASONING MECHANISM FOR CONSTRUCTION MEDIATION
}

\author{
Chun-Yi Hwang $^{1 *}$ and Nie-Jia Yau ${ }^{2}$ \\ ${ }^{1}$ Ph.D. candidate, Graduate Institute of Construction Eng. and Management, National Central University, \\ Taiwan \\ ${ }^{2}$ Professor, Graduate Institute of Construction Engineering and Management, National Central University, \\ Taiwan \\ * Corresponding author (junteng.hwang@gmail.com)
}

\begin{abstract}
Chinese mediation mechanism has long been relied to resolve every kind of disputes from Western Zhou Dynasty (1046-771 BC). Contemporary Taiwanese legal system inherits this invaluable culture and introduces foreign laws into its legal system. Since dispute board (DB) and the way to enforce its decisions has been widely discussed recently, this article treasures this opportunity to evaluate current mediation statutes in Taiwan and the trend of DB after reviewing relevant methodologies and systems for mediation result and reasoning. Based on available mediation and/or litigation cases, this study attempts to use case-based reasoning (CBR) methodology to predict the possible outcome of a mediation case by finding the similarity between current case and historical cases. The predicted outcome can serve as a reference for making decisions in future mediation process. Finally, some unique features in using such methodology for prediction of mediation decisions are also discussed.
\end{abstract}

Keywords: Construction Dispute Resolution, Dispute Board, Mediation, Case-based Reasoning.

\section{INTRODUCTION}

The construction industry is one of knowledge-intensive industries. Therefore, construction disputes and claims are hard to be avoided in most construction projects due to its complexity and diverging interests of the involved parties. Researchers have tried to develop several methodologies for mitigation of construction disputes. Mediation is one of effective ways to resolve construction disputes through project life circle, and case-based reasoning methodology offers a reasoning model that similar to the manner many people solve problems. Based on many past researches, it shows that a successful decision support system for construction mediation would improve accuracy of retrieval cases and reduce retrieval time. The main goal of this study is to investigate CBR for retrieving similar cases and predict the possible outcome of a mediation case by finding the similarity between current case and historical ones. The local mediation mechanism is reviewed, and a sample case is presented to analyze the feasibility of such system in civil law jurisdiction, such as Taiwan and Mainland China.

\section{LITERATURE AND MECHANISM REVIEW}

\subsection{Dispute Resolution Support Systems}

Researchers has developed many methodologies and systems for judicial results and reasoning by utilizing the Artificial Intelligence (AI). These decision support mechanisms are useful to assist judges and neutral third parties for predicting and resolving construction disputes. Over the last decade, a series of new and modified methods have been developed to improve the prediction of the results and support better the progress of dispute resolution. In 2003, Chen, J. developed a Litigation Prediction Model (LPM) to predict the trend of litigation caused by change disputes. The classification rate reaches as high as $90 \%$ [1]. Then, El-adaway built up a way for using logical induction decision support in 
construction claims and disputes in 2008. He also tried to simulate legal discourse in construction disputes. His multiagent system for construction dispute resolution (MAS-COR) was then created [2]. In 2009, Cheng et al. further refined and improved the case-based reasoning model by combined it with fuzzy-set theory to establish the fuzzy case-based reasoning model (FCBR) for construction dispute settlement support system [3]. After that, Pulket and Arditi suggested Universal Prediction Model (UPM) for construction litigation. Pulket and Arditi found that UPM provided a higher prediction rate than those obtained in previous studies [4]. Recently, through analyzing legal factors of construction precedent cases, Mahfouz and Kandil utilized support vector machines to propose Automated Prediction Model for construction litigations through Support Vector Machine modeling (SVM) for better analyzing the outcome of construction litigation in 2010. The authors claimed the accuracy can be as high as 98\% [5]. The aforesaid systems are all developed to assist making better decisions for resolving construction disputes.

\subsection{Mediation Mechanism in Taiwan}

\subsubsection{Institutional Mediation}

Several mediation alternatives are available in contemporary Taiwan, such as public mediation, mediation by arbitration association, court sponsored mediation, dissatisfaction complaint, and complaint review board, etc. Mediation can be categorized into two main types: institutional mediation and non-institutional mediation. Non-institutional mediation is a mediation in which the selected neutral third party mediator does not belong to any institutional mediation board. Conversely, institutional mediation shall select members of an institutional mediation board to serve as neutral third party mediator. Comparing to non-institutional one, this type of mediation is utilized more and more in Taiwan. Through the help of mediators, almost every kind of construction disputes can be resolved legally and amicably.

Most of counties, townships, cities and districts offer public mediation at no cost of complainants in Taiwan.
Since mediators of institutional mediation board are leaders of neighborhood, disputants value their opinions and hardly ever question their fairness. It certainly helps the forming of a mutual agreement. Contrast to free service of public mediation, mediation fee set by the arbitration association is usually paid by the applicant if no other agreement existed. Another type of mediation service is offered by Taiwan civil courts in accordance with Article 406-1 of Taiwan Code of Civil Procedure. The court sponsored mediation can be conducted outside of the courtroom, and the litigation proceeding shall be stayed during the period of court sponsored mediation. There is no time constraint on the mediation. When the involved parties fail to reach agreement, the litigation process shall resume accordingly. Though the plaintiff may move for the return of one half of the court costs paid after successful mediation, disputants shall still pay a mediation fee attached to such court service. Beyond the advantage of lower service fee and almost no time constraint, institution mediation may resolve construction disputes as efficient as litigation and arbitration. However, mediation findings are binding only when the original copies of the written agreement of mediation have been sent to the court for review and approved. Contrast to the mediation mechanism which mitigates sufferers mostly after the completion of project, Dispute Review Board (DRB) can be formed ahead of the beginning of construction. It has been used broadly in the U.S. The statistic shows that the success rate of the DRB process is 98.7\% and no disputes requiring hearings were brought to the DRB for $58 \%$ of the projects [6]. Nonetheless, the mechanism of DRB, Dispute Adjudication Board (DAB), Combined Dispute Board (CDB), and DB are being introduced into Taiwan just lately. Among them, DRB has been applied in the public sector first. The Chinese Arbitration Association, one of four arbitration associations in Taiwan announced its DRB rules in 2009. It has put great effort to promote the DRB mechanism after that. 


\subsubsection{Public Work Mediation}

Pursuant to Paragraph 5 of Article 80 of the Government Procurement Act, a supplier may file a written dissatisfaction complaint with the Complaint Review Board for Government Procurement (CRBGP) or CRBGP of Public Construction Commission (PCC) of the Executive Yuan in Taiwan after filing a protest to the procurement agency.

In order to further balance the power and right between government agencies and contractors, the mandatory mediation-arbitration mechanism is introduced into public work in Taiwan. In July of 2007, Article of 85-1 of Government Procurement Act is promulgated. Its subparagraph (2) of article 23 regulates, "In the event that the application for mediation referred to in the preceding paragraph is made by the supplier, the entity may not object to such application. In the event that the unsuccessful mediation of construction work due to the entity does not agree with proposal or resolution for mediation proposed by CRBGP, the entity may not object to the arbitration filed by the supplier.” To some extent, the mechanism conflicts with the free spirit of mediation since this mediation-arbitration mechanism forces the government agencies to join mediation and arbitration if it does not agree with proposal or resolution for mediation proposed by CRBGP. Though the involved entities still have choice to insist on their own opinion by rejecting all mediation decisions, this mechanism assist to resolve aforesaid disputes successfully. The following Table 1 shows statistics of Complaint Review and mediation for government procurement in Taiwan [7].

Table 1 Statistics of results of CRBGP and Mediation in Taiwan (May 27, 1999 Sep. 9, 2000)

\begin{tabular}{|c|l|c|c|}
\hline \multirow{2}{*}{$\begin{array}{l}\text { Mediation } \\
\text { Cases }\end{array}$} & Sustained & 145 cases & $49.7 \%$ \\
\cline { 2 - 4 } & Partial Sustained & 81 cases & $27.7 \%$ \\
\cline { 2 - 4 } & Not sustained & 66 cases & $22.6 \%$ \\
\hline \multirow{2}{*}{ Total } & \multicolumn{2}{|l}{292 cases } & \\
\hline
\end{tabular}

\section{CASE-BASED REASONING METHODOLOGY}

\subsection{CBR Model}

CBR methodology offers a reasoning prototype that is similar to the method many people solve problems habitually. It has been widely utilized in nearly all profession, such as business management, legal, engineering, healthcare, etc. Anyhow, a CBR reasoner resolves new disputes by referring to binding or unbinding mediation decisions and reasoning of historical dispute cases. Principle of Stare decisis has been applied in Common Law System for long time. The spirit of CBR copes with this principle. CBR help decision makers to choose most suitable alternative cases through accumulated judicial judgments. In addition, utilizing this human-like or artificial intelligence (AI) type of system, the experts and researchers may predict the result of the dispute resolution much more precisely and easily. In 2006, Chau indicated the result of the case-based reasoning model approach could predict $80 \%$ of the outcome of construction claims successfully [8]. Some hybrid or improved methods even claims higher rate of success.

\subsection{Feasibility of CBR on Mediation in Taiwan}

The result and process of CBR analyses is quiet similar to the judgments rendered by common law courts. Due to its similar characteristic, CBR mythology is appropriate to predict the result of construction disputes resolution in common law countries undoubtedly. Anyhow, due to the nature of different legal systems, it is a challenge to apply the CBR mythology, comparing to rule-based reasoning one (RBR), in civil law System. In order to take the advantages of un-codified (or CBR) legal system on top of existing codified (or RBR) legal system, researchers put more effort for achieving the goal recently. Taiwan, same as Mainland China, is a civil law jurisdiction which received the legal systems of continental Europe mostly. Lately, researchers have tried to apply CBR methodology to its codified legal system which is similar to RBR system. Beyond imagination, the prediction outcome of CBR model is successful to an acceptable degree in several local researches. It indicates CBR methodology is not only applicable in common law system, but also performs well in civil law System. 


\subsection{The CBR Framework}

Basically, CBR model users shall retrieve similar cases from most recent dispute cases to remember or organize their reasoning for resolving their on-going cases. Therefore, a pool of historical cases of construction dispute shall be collected first. Then, the cases shall be indexed carefully for retrieving easily later according to the special features of construction disputes. When a dispute arises during the life circle of a construction project, the CBR user then chooses cases which have similar critical attributes as current one from the pool. After that, the user may arrive at his/her decision based on the outcome of the historical cases. Finally, the system administrator shall update the database of historical dispute cases regularly for future uses.

\subsection{Application of CBR Model}

\subsubsection{Sample Case}

Since no comprehensive CBR model and case bank in English is designed mainly for resolve mediation disputes in civil law countries, hereinafter, the Law and Regulations Retrieving System of Judicial Yuan, http://jirs.judicial.gov.tw/Index.htm, serves as the roll of a decision support system instead of an English mediation CBR model [9]. The advantage of this arrangement is that the sample mediation case does not include in this case-based Chinese retrieving system, so it can be the testing sample of the system. The sample local mediation case is provided as an example to explain how a CBR model works. Though mediation findings and court judgments are somewhat different, but the sample case can also help to exams the feasibility and effectiveness of similar kind retrieving systems as a mediation CBR system applied in the same condition.

The background of the sample case is elaborated as follows. Several years ago, PCC had outlined procedures for handling construction price adjustments for all government construction contracts to compensate losses of contractors from material price escalation. Pursuant to the procedures, other government agencies draft their contract terms accordingly to provide construction cost escalation for all material cost changes and cover contractors' actual added cost of increased material costs. The sample case is regarding to a private construction corporation (hereinafter referred to as "Contractor”) files a construction mediation application to the CRBGP of Taipei City Government after failure of its negotiation with one of departments of Taipei City Government (hereinafter referred to as “Owner”).

\subsubsection{Attributes of Cases}

The CBR analysis initiates from collecting cases into case bank and then indexing them. The 28 identified attributes, by interviewing three construction and legal practitioners, are showed in Table 2. They are classified into seven categories mainly by nature of disputes and arguments. The types of attribute value is binary since the binary attribute implies the dispute of the sample case is relevant to it or not (i.e. cost escalation). If there is no relevance between the sample case and the case in case bank, the value is 0 ; otherwise, it is 1 . The sample case involves seven aforementioned attributes.

Table 2 Attributes and Values in Mediation CBR

\begin{tabular}{|c|c|c|c|}
\hline \multirow[t]{2}{*}{ \# } & \multirow[t]{2}{*}{ Classification } & \multicolumn{2}{|l|}{ Attribute } \\
\hline & & Name & Value \\
\hline 1 & $\begin{array}{r}\text { Decision } \\
\text { Ground }\end{array}$ & $\begin{array}{l}\text { Contract, Jurisprudence, } \\
\text { Customs, Act. }\end{array}$ & $\begin{array}{c}\text { Binary } \\
(0 / 1)\end{array}$ \\
\hline 2 & $\begin{array}{l}\text { Schedule } \\
\text { Involved }\end{array}$ & $\begin{array}{l}\text { CPM, Coordination, Concurrent } \\
\text { Delay, Disaster. }\end{array}$ & Binary \\
\hline & $\begin{array}{l}\text { Damage } \\
\text { Measured }\end{array}$ & $\begin{array}{l}\text { Cost Escalation, Advance } \\
\text { Payment, Late Payment, } \\
\text { Compensatory Liquidated } \\
\text { Damage, Punitive Liquidated } \\
\text { Damage. }\end{array}$ & Binary \\
\hline & $\begin{array}{l}\text { Quality } \\
\text { Involved }\end{array}$ & $\begin{array}{l}\text { Alternative Material, } \\
\text { Supervision. }\end{array}$ & Binary \\
\hline 5 & $\begin{array}{c}\text { Change } \\
\text { Order }\end{array}$ & Directed, Constructive, Scope. & Binary \\
\hline & $\begin{array}{l}\text { Contract } \\
\text { Type }\end{array}$ & $\begin{array}{l}\text { Lump Sum, Unit Price, Cost } \\
\text { plus Fee, Time Rate Pay, } \\
\text { Percentage of Construction } \\
\text { Expense. }\end{array}$ & Binary \\
\hline & $\begin{array}{l}\text { Other Dis- } \\
\text { agreement }\end{array}$ & $\begin{array}{l}\text { Contract Interpretation, } \\
\text { Unknown Site Condition, } \\
\text { Misrepresentation of Site. }\end{array}$ & Binary \\
\hline
\end{tabular}


The similarity between the queried disputes (a) in sample case (i) and a case (j) is defined as the sum of the local resemblances of its integral attributes (LSa) multiplied by their relevance weights (Wa) and divided by the total relevance weights.

Similarity $(\mathrm{i}, \mathrm{j})=\frac{\sum_{a=1}^{n} W a \times L S a_{(i, j)}}{\sum_{a=1}^{n} W a}$

The weights of seven attribute (a) in the sample case (shown in Table 3) are left to be specified by the user of CBR system.

Table 3 Designated Weights of Attributes

\begin{tabular}{|r|l|r|}
\hline$\#$ & \multicolumn{1}{|c|}{ Attribute } & Weight \\
\hline 1 & Contract & 4 \\
\hline 2 & Jurisprudence & 3 \\
\hline 3 & Act & 4 \\
\hline 4 & Cost Escalation & 5 \\
\hline 5 & Compensatory Liquidated Damage & 4 \\
\hline 6 & Lump Sum & 5 \\
\hline 7 & Contract Interpretation & 4 \\
\hline
\end{tabular}

\subsubsection{Retrieving and Selecting}

By means of the attributes of the sample case, the CBR system retrieves cases, from all cases of the Law and Regulations Retrieving System of Judicial Yuan. It finds 18 related cases among 865 construction cases. Among them, three cases have $100 \%$ similarity comparing to our sample case (refer to Case 1 of Table 4). The only differences are the respondents, other government agencies. On the other hand, some cases have low similarity, as low as $28 \%$ (refer to Case 2 of Table 4). Most of them are related the attorney fee though they are classified into the attribute of cost escalation.

Table 4 Similarity (S) of Sample Case

\begin{tabular}{|l|l|r|r|r|r|}
\hline$\#$ & \multicolumn{1}{|c|}{ Attribute } & Case 1 & \multicolumn{1}{c|}{ S } & Case 2 & S \\
\hline 1 & Contract & 1 & 4 & 1 & 4 \\
\hline 2 & Jurisprudence & 1 & 3 & 0 & 0 \\
\hline 3 & Act & 1 & 4 & 0 & 0 \\
\hline 4 & Cost Escalation & 1 & 5 & 0 & 0 \\
\hline 5 & $\begin{array}{l}\text { Compensatory Liquidated } \\
\text { Damage }\end{array}$ & 1 & 4 & 0 & 0 \\
\hline 6 & Lump Sum & 1 & 5 & 0 & 0 \\
\hline 7 & Contract Interpretation & 1 & 4 & 1 & 4 \\
\hline Total & 7 & 29 & 2 & 8 \\
\hline Similarity & \multicolumn{2}{|c|}{$100 \%$} & \multicolumn{2}{|c|}{$28 \%$} \\
\hline
\end{tabular}

\subsubsection{Investigation of Prediction}

After retrieving best match cases, the reasoning behind the case can then be utilized to predict the possible outcome of a mediation case. The predicted outcome can serve as a reference for making decisions in future mediation process. In the sample case, considering rights of parties and completeness, fairness and equitableness, the mediators recommended to revise Article 76 of the Supplementary Instructions to Bidders to be: “The construction payment shall be adjusted by published cost indices. The payment of the specific items would be 'increased' accordingly if the change of their respective cost index were over $0 \%$. The payment of the foresaid items would be 'decreased' accordingly if the change of their respective cost index were over 2.5\%. Finally, both parties agreed on the revision.

Since this type of CBR retrieving system can be expanded to be a decision support system to predict mediation outcomes and provide relevant information, such as reasoning of mediators or judges, it can be helpful to decision makers. Especially, some commercial law systems as LexisNexis and Westlaw International, already equipped with excellent retrieving functions for most areas of law in most Anglo-American jurisdictions. The researchers may consider inserting or attaching a function of prediction in these systems to help construction professionals. However, the different background reasoning and expertise between mediation findings and judgments, such unbinding over binding and lack of construction expertise, would certainly decrease the success rate of predictions. It is left for future researches to explore the way to overcome these differences.

\section{CONCLUSIONS}

Mediation is one of effective methodologies for mitigation of construction disputes not only in private project, but also in public work. Moreover, case-based reasoning methodology offers a practicable prediction and reasoning model for resolving construction disputes. In this regard, this research has investigated CBR for retrieving similar cases and predicting the possible 
outcome under the civil law jurisdiction. During the retrieving process, the differences between construction disputes and others do not influence the effectiveness of the decision support system much if appropriate trade language were used. Although the contribution of this work does not reside on compilation of an enormous case bank, it is worthy of noticing that a CBR mythology does help decision makers to assess valuable historical cases in the process of mediation efficiently. However, in order to improve accuracy of retrieval cases and reduce retrieval time, selection of attributes would play the key role. Furthermore, competence of evidence shall be considered in future models and studies.

\section{REFERENCES}

[1] Chen, J., Litigation Prediction Model for Construction Disputes Caused by Change Orders, Dissertation of University of Wisconsin at Madison, 2003. [2] El-adaway, H., Construction dispute mitigation through multi-agent based simulation and risk management modeling, Dissertation of Iowa State University, 2008.

[3] Cheng, M., Tsai, C. and Chiu, Y., "Fuzzy case-based reasoning for coping with construction disputes”, Expert Systems with Applications, Vol.36(2), Part 2, pp. 41064113, March 2009.

[4] Pulket, T. and Arditi D., "Universal Prediction Model for Construction Litigation”, Journal of Computing in Civil Engineering, Vol.23(3), pp. 178-187, May/June 2009.

[5] Mahfouz, T. and Kandil, A., "Automated outcome prediction model for differing site conditions through support vector machines”, Proceedings of the International Conference on Computing in Civil and Building Engineering, 2010.

[6] Dispute Resolution Board Foundation, “1.3 Benefits”, DRBF Practices and Procedures, DRBF Research, p.3, April 2007.
[7] Public Construction Commission, Complaint Review for government procurement in Taiwan, PCC Research, p.39 \& p.41, 2000.

[8] Chau K. W., "Prediction of Construction Litigation Outcome - A Case-Based Reasoning Approach”, Advances in Applied Artificial Intelligence, Vol.4031, pp. 548-553, 2006.

[9] The Judicial Yuan of the Republic China, "Law and Regulations Retrieving System, http://jirs.judicial.gov.tw/eng/, 2011. 